\title{
Reflex sympathetic dystrophy of the upper limb: Treatment using a series of stellate ganglion blocks
}

\author{
MM Al-Qattan FRCSC, A Wahood MD \\ Division of Plastic Surgery and the Department of Anaesthesia, King Saudi University and King Fahad \\ National Guard Hospital, Saudi Arabia
}

\begin{abstract}
MM Al-Qattan, A Wahood. Reflex sympathetic dystrophy of the upper limb: Treatment using a series of stellate ganglion blocks. Can J Plast Surg 2000;8(4):139-142.

Fourteen consecutive patients with reflex sympathetic dystrophy of the hand were studied. Their conditions were diagnosed based on clinical features alone and confirmed by a positive symptomatic response following a stellate ganglion test block. Treatment for all patients was a series of stellate ganglion blocks combined with a physiotherapy program. The number of blocks performed per patient ranged between three and nine blocks, and the blocks were performed at two- to 10-day intervals. Subjectively, patients were asked to rate pain before and after treatment on a scale of 0 (no pain) to 10 (unbearable pain). Objectively, the average total active motion of the fingers (ATAM) was compared before and after treatment. Before treatment, pain was rated between 7 and 10, and the ATAM of the fingers was $83^{\circ}$. After treatment, pain was rated between 0 and 2 , and motion improved to $260^{\circ}$. It was concluded that stellate ganglion block is an effective and safe method of treating reflex sympathetic dystrophy as long as the diagnosis is made early, the block is given by an experienced physician and multiple blocks are performed along with a physiotherapy program.
\end{abstract}

Key Words: Reflex sympathetic dystrophy; Stellate ganglion

\section{Algodystrophie sympathique réflexe du membre supérieur : série de traitements anesthésiants des ganglions cervico-thoraciques}

RÉSUMÉ : Quatorze patients consécutifs souffrant d'algodystrophie sympathique réflexe de la main ont participé à l'étude. Le diagnostic a été posé à partir du tableau clinique seulement, puis confirmé par une réaction symptomatique positive à une épreuve d'anesthésie des ganglions cervico-thoraciques. Le traitement se composait pour tous les patients d'une série de traitements anesthésiants des ganglions cervico-thoraciques, associée à un programme de physiothérapie. Le nombre de traitements par patient variait de trois à neuf, et ceux-ci étaient effectués à des intervalles de deux à dix jours. Subjectivement, on a demandé aux patients d'évaluer la douleur sur une échelle de 0 (pas de douleur) à 10 (douleur insupportable) avant et après le traitement. Objectivement, on a comparé la mobilité active totale moyenne des doigts avant et après le traitement. Avant le traitement, la douleur oscillait entre 7 et 10 et la mobilité des doigts n'était que de $83^{\circ}$; après le traitement, la douleur oscillait entre 0 et 2 et la mobilité des doigts avait augmenté jusqu'à 260 . On peut donc conclure que le traitement anesthésiant des ganglions cervico-thoraciques s'avère un moyen sûr et efficace de soulager l'algodystrophie sympathique réflexe pourvu que le diagnostic soit posé tôt, que les traitements anesthésiants soient administrés par un médecin chevronné et que ceux-ci soient accompagnés d'un programme de physiothérapie.

$\mathrm{R}$ eflex sympathetic dystrophy (RSD) is a complex syndrome with a plethora of signs and symptoms that vary, both among individuals and with the progression of the disease over time (1). Five clinical types of RSD are recognized, including minor causalgia, minor traumatic dystrophy, shoulder hand syndrome, major causalgia and major traumatic dystrophy. The term 'causalgia' (burning pain) is reserved to reflect RSD arising from nerve injury, while 'traumatic dystrophy' occurs as a result of injury to soft tissue, joints or bone, rather than damage to a specific nerve (1).

Recently, a consensus group met in Orlando, Florida and revised the old system for the classification of pain syndromes previously called RSD. The new system employs the term 'complex regional pain syndrome' (CRPS), which is divided into two types as shown in Table 1. Type I reflects what 
TABLE 1

Complex regional pain syndrome

\begin{tabular}{ll}
\hline Specific criteria for type I & $\begin{array}{c}\text { Develops after an initiating noxious } \\
\text { event other than a nerve injury } \\
\text { Develops after a nerve injury }\end{array}$ \\
$\begin{array}{l}\text { Common criteria for both types } \\
\text { I and II }\end{array}$ & $\begin{array}{l}\text { a) Spontaneous pain or allodynia/ } \\
\text { hyperalgesia* } \\
\text { b) Evidence of edema, skin blood } \\
\text { flow abnormality or abnormal su- } \\
\text { domotor activity }\end{array}$ \\
\hline
\end{tabular}

*Allodynia is pain associated with light touch to the skin; hyperalgesia is increased sensitivity to stimulation that includes pain or response to any mild non-noxious stimulus

most clinicians describe as typical RSD, whereas type II refers to patients who sustain a nerve injury and later develop a pain syndrome (causalgia). The participants in the consensus conference also stated that the term 'sympathetically maintained pain' (SMP) should be considered a variable phenomenon associated with a variety of pain disorders, including CRPS types I and II $(2,3)$.

A series of patients with CRPS type I who were treated with multiple stellate ganglion blocks is reported.

\section{PATIENTS AND METHODS}

Fourteen consecutive patients with CRPS of the upper limb comprised the study. There were five males and nine females. Ages ranged between 28 and 65 years (mean 38 years). The initiating event before the onset of pain is shown in Table 2 . All patients met the clinical criteria for diagnosis of CRPS type I (Table 1).

The diagnosis was made by the hand surgeon and was based on clinical features alone; none of the patients underwent pain threshold evaluation, bone scan, magnetic resonance imaging, laser Doppler/perfusion studies or a specific test for sudomotor activity. Thirteen of 14 patients presented and underwent treatment within three months from the onset of pain. The remaining patient was seen and treated 10 months after injury. Treatment in all patients was by a series of stellate ganglion blocks and physiotherapy. All blocks were performed by the same anesthetist.

\section{Stellate ganglion block technique}

The detailed description of stellate ganglion block is beyond the scope of this paper and can be found in the literature (2). Briefly, the sixth cervical vertebral tubercle is palpated lateral to the cricoid cartilage. The anesthetist then places the index and middle fingers between the carotid artery laterally and the trachea medially at the level of $\mathrm{C} 6$, then a 22 -gauge needle is inserted between the fingers until it contacts the transverse process of C6. The needle is then withdrawn $2 \mathrm{~mm}$ before injection. This study's anesthetist routinely uses the combination of $10 \mathrm{~cm}^{3}$ of $0.5 \%$ bupivacaine, $5 \mathrm{~cm}^{3}$ of $2 \% \mathrm{xy}-$ locaine and $5 \mathrm{~g}$ of sufentanil for injection. The interruption of sympathetic firing by the block was demonstrated by the presence of Horner's syndrome (ipsilateral ptosis and myosis), dryness of the skin of the face and hand, and the subjec-
TABLE 2

The initiating event before the onset of pain in 14 consecutive patients with reflex sympathetic dystrophy

\begin{tabular}{lc}
\hline Event & Number of patients \\
\hline latrogenic injury (surgery) & 1 \\
Trigger finger release & 1 \\
Metacarpal osteotomy for scissoring deformity & 1 \\
Skin graft for finger contractures & 1 \\
Synovectomy & \\
Noniatrogenic injury & 3 \\
Fracture of the fingers & 7 \\
Fracture of the forearm bones & \\
\hline
\end{tabular}

tive feeling of warmth of the limb. The number of blocks performed per patient ranged between three and nine blocks (mean five blocks), and the blocks were performed at two- to 10-day intervals (mean four-day interval).

\section{Assessment of results}

All patients were followed up for a minimum of six months. Results were assessed both subjectively and objectively. Subjectively, the patient was asked to rate pain before and after treatment on a scale of 0 (no pain) to 10 (unbearable pain). Objectively, the average total active motion (ATAM) of the metacarpophalangeal, proximal interphalangeal and distal interphalangeal joints of the four fingers was compared before and after treatment.

\section{RESULTS}

Before treatment, pain was subjectively rated between 7 and 10 (mean 8 ), and after treatment, it was rated between 0 and 2 (mean 1).

On follow-up, pain recurred in one patient who rated the recurrent pain as 4 . This patient underwent another four blocks given over a period of two weeks, and an adequate sustained relief of pain (rated as 1) was achieved following the second series of ganglion blocks.

The ATAM of the fingers before treatment was 83 . After treatment, the ATAM improved to 260 in the 13 patients who were treated within three months of pain onset, and an average result is shown in Figure 1. The remaining patient, who presented late (10 months after release of trigger little and ring fingers), had persistent flexion contractures of the interphalangeal joints of the little and ring fingers despite the relief of pain. This patient underwent surgical release of these two fingers six months later to obtain a more functional position of the fingers. It was interesting to note that this patient did not experience recurrent pain following the second surgical procedure and no prophylactic blocks were performed.

\section{DISCUSSION}

The diagnosis of RSD in our patients was based on clinical features alone. Other authors have described several investigations to confirm the diagnosis, including $\mathrm{x}$-ray, magnetic resonance imaging, three-phase bone scan, vascular scan, phosphorus 31-nuclear magnetic resonance spectros- 

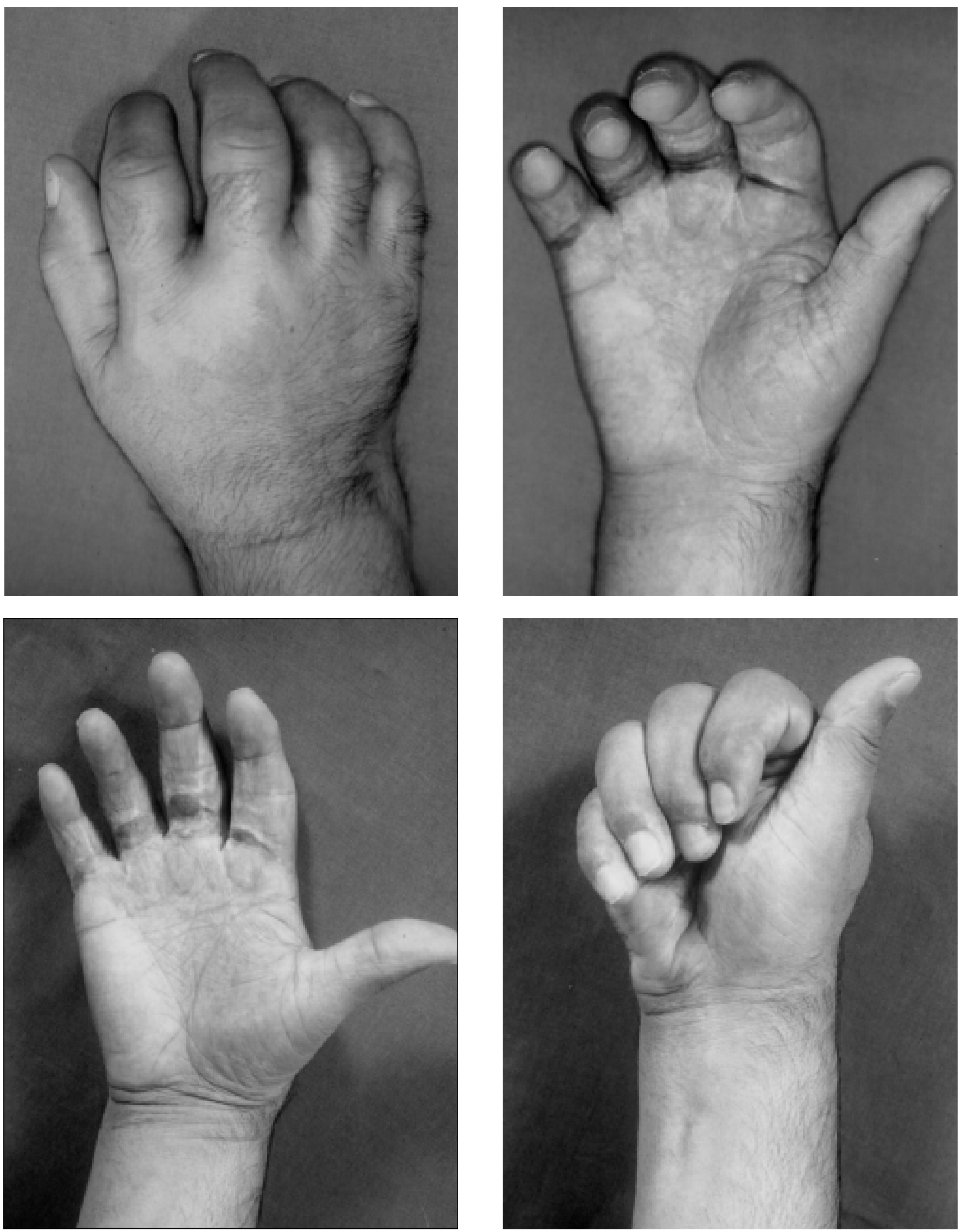

Figure 1) A 40-year-old man who developed reflex sympathetic dystrophy following release of contracture and skin graft of the fingers. Top left and right Appearance of the hand at the time of presentation to the authors. Bottom left and right Appearance of the hand three weeks after six stellate ganglion blocks 
copy and indium-III immunoglubulin scintigraphy (4-7). These diagnostic tests, however, are not essential for diagnosing RSD. Furthermore, none of the tests has a 100\% sensitivity or specificity. In our series, once RSD was suspected clinically, the patient underwent a stellate ganglion test block. The positive clinical response to this test block simply confirmed the diagnosis, and the remaining series of blocks were then completed.

The number and frequency of blocks varied and were based on the clinical response. The reason for this variability remains unknown, and we did not find a correlation between the severity of presenting symptoms and the total number of blocks required.

In our series, interruption of sympathetic firing by the block was demonstrated by the presence of Horner's syndrome, and dryness and warmth of the hand. Even in the presence of these signs, it is estimated that only $70 \%$ to $75 \%$ of the postganglionic sympathetic axons in the upper extremity are blocked with a routine stellate ganglion block (1). This may explain why multiple blocks are required for every patient.

Another important point to realize is that a stellate ganglion block should be performed by an experienced physician in a hospital setting, and complications of stellate ganglion blocks should never be underestimated. The vertebral artery runs close to the transverse process of $\mathrm{C} 6$, and intravascular injection must be avoided. The recurrent laryngeal and phrenic nerves may also be blocked if needle position is not ideal. Finally, if the injection is deposited posterior to the prevertebral fascia, partial brachial plexus block can occur.

In our series, a combination of bupivacaine, xylocaine and sufentanil was used for the injections. Bupivacaine blocks the sympathetic fibres for 6 to $10 \mathrm{~h}$, which allows sufficient time for physiotherapy to be performed following the nerve block.

Stellate ganglion block is just one of several methods for treating RSD. Others include oral medications (such as analgesics, anti-inflammatory drugs, calcitonin and antidepressants), somatic (axillary or interscalene) nerve blocks, regional intravenous sympathetic nerve blocks (such as guanethidine block) and electrical stimulation (1,8-10). None of these methods was used in our patients.

\section{CONCLUSIONS}

Stellate ganglion block is an effective and safe method of treating RSD of the upper limb as long as the condition is diagnosed and treated early, the block is given by an experienced physician and multiple blocks are performed along with a physiotherapy program.

\section{REFERENCES}

1. Soucacos PN, Diznitsis LA, Beris AE, Xenakis TA, Malizos KN. Reflex sympathetic dystrophy of the upper extremity. Clinical features and response to multimodal management. Hand Clin 1997;13:339-54.

2. Brown DL. Somatic or sympathetic block for reflex sympathetic dystrophy. Which is indicated? Hand Clin 1997;13:485-97.

3. Wong GY, Wilson PR. Classification of complex regional pain syndromes. New concepts. Hand Clin 1997;13:319-25.

4. Doury PC. Algodystrophy. A spectrum of disease, historical perspectives, criteria of diagnosis, and principles of treatment. Hand Clin 1997; 13:327-37.

5. Driessens M. Infrequent presentations of reflex sympathetic dystrophy and pseudodystrophy. Hand Clin 1997;13:413-22.

6. van der Laan L, Goris RJ. Reflex sympathetic dystrophy. An exaggerated regional inflammatory response? Hand Clin 1997;13:373-85.

7. Schiepers C. Clinical value of dynamic bone and vascular scintigraphy in diagnosing reflex sympathetic dystrophy of the upper extremity. Hand Clin 1997;13:423-9.

8. Arlet J, Mazieres B. Medical treatment of reflex sympathetic dystrophy. Hand Clin 1997;13:477-83.

9. Cooney WP. Electrical stimulation and the treatment of complex regional pain syndromes of the upper extremity. Hand Clin 1997;13:519-26.

10. Farcot JM, Gautherie M, Foucher G. Regional intravenous sympathetic nerve blocks. Hand Clin 1997;13:499-517. 